\title{
Como ocorrem as inovações em serviços? Um estudo exploratório de empresas no Brasil
}

\section{Understanding how innovation takes place in service companies - An exploratory study of companies in Brazil}

\author{
Luís Henrique Rigato Vasconcellos ${ }^{1}$ \\ Roberto Marx ${ }^{2}$
}

\begin{abstract}
Resumo: O objetivo deste artigo é o de buscar uma melhor compreensão sobre o fenômeno da inovação nas empresas de serviços. Procurou-se seguir uma linha de abordagem segundo a qual, para se estudar e compreender o funcionamento do processo inovativo nestas empresas, se faz necessário um estudo com maior profundidade nas organizações, investigando como ocorreram - em detalhes - as inovações. Para essa finalidade foram conduzidos estudos de casos em cinco diferentes organizações de serviços no setor de telecomunicações e atividades de informática no Brasil. Para melhor descrever o processo de inovação foi empregado o conceito de cadeia de inovação proposto por Hansen e Birkinshaw (2007), isto é, uma visão expandida do fenômeno da inovação que forma uma espécie de cadeia composta pelas seguintes fases: geração de ideias (intradepartamental, interdepartamental e interinstitucional); a conversão (seleção de ideias, incluindo a triagem, o financiamento e o desenvolvimento) e a difusão (sua disseminação na organização e no mercado). Por meio dos casos percebeu-se também que a inovação em serviços segue uma lógica similar em relação às inovações encontradas na literatura para bens físicos, sobretudo no que se refere ao uso da metodologia dos Stage-Gates proposto por Cooper (1993).
\end{abstract}

Palavras-chave: Inovação. Serviços. Cadeia de valor da inovação.

\begin{abstract}
The main objective of this paper is to improve the understanding of the phenomenon of innovation in service companies. It focuses on the idea that in order to study and understand how innovation processes take place, a more in depth study of these companies was required. Several case studies were conducted in five different service enterprises in the sector of telecommunications and computer-related activities. To describe the innovation process, the concept of "Chain of Innovation" proposed by Hansen and Birkinshaw (2007) was applied, i.e. an expanded view of the phenomenon of innovation that forms a type of chain composed by the following phases: generation of ideas; conversion (selection of ideas, including the selection, financing, and development), and diffusion. Through the cases studied, it can be seen that innovation in services follows a similar logic to that found in the literature for physical goods, especially concerning the use of the Stage-Gates' classic model proposed by Cooper (1993).
\end{abstract}

Keywords: Innovation. Service Companies. Value chain innovation.

\section{Introdução}

\subsection{Inovação em serviços: da generalização do termo à proposição de uma definição alternativa}

Desde que Schumpeter (1938) classificou as inovações em radicais (aquelas que tendem a provocar grandes mudanças no mundo) ou incrementais (aquelas que promovem continuamente o processo de mudança) inúmeras definições sobre o tema de inovação surgiram na literatura (ROGERS; SHOEMAKER, 1971; EDQUIST, 1997; SUNDBO; GALLOUJ, 1998). Para se chegar a uma definição conceitual sobre o que se está denominando inovação em serviços neste artigo, parece recomendável um maior aprofundamento dessa questão.

Uma tentativa de consolidação de conceitos permitindo a criação de indicadores comparativos sobre o tema de inovação (tecnológica) entre diversos países foi o Manual de Oslo em 1992. Para este manual, uma inovação tecnológica é a implantação/ comercialização de um produto com características de desempenho aprimoradas, de modo a fornecer

\footnotetext{
${ }^{1}$ Fundação Getúlio Vargas, Rua Itapeva, 474, $8^{\circ}$ andar, São Paulo, SP, Brasil, e-mail: luis.vasconcellos@ fgv.br

${ }^{2}$ Escola Politécnica da Universidade de São Paulo, Av. Professor Almeida Prado, Travessa 2, 128, Cidade Universitária, CEP 05508-900, São Paulo, SP, Brasil, e-mail: robmarx@usp.br
} 
objetivamente ao consumidor serviços novos ou aprimorados. Muitas das definições de Schumpeter foram seguidas nesse manual, como a que propõe quatro tipos básicos de inovação, a saber: produto, processo, marketing e organizacional, conforme mostrado no Quadro 1. Entretanto a classificação proposta no manual de Oslo não parece ser muito precisa quando aplicada ao setor de serviços. Para exemplificar, quando uma empresa de televisão por assinatura lança um novo "pacote integrado" que combina simultaneamente o acesso para o usuário final de banda larga de internet e o fornecimento de um provedor gratuito, além do acesso a canais de TV pagos, estaria a empresa promovendo uma inovação de produto (já que nenhuma outra operadora dispõe de um produto semelhante) ou uma inovação de marketing (já que os produtos já existem, mas o que houve foi a promoção dos valores dos itens num pacote agregado num valor financeiro reduzido)?

É preciso lembrar também que a própria inclusão da inovação de marketing é relativamente recente no Manual de Oslo. Segundo este manual:

Embora haja menos experiências com inovações de marketing vis-à-vis as inovações organizacionais, discussões sobre mudanças em marketing foram incluídas em várias pesquisas sobre inovação, e há campos de teste dos conceitos de marketing em diversos países [...] Uma característica que define inovações de marketing é o fato de estarem orientadas aos consumidores e mercados, com o objetivo de incrementar as vendas e a fatia de mercado. Esses objetivos econômicos podem ser muito diferentes daqueles ligados a inovações de processo, que tendem a focar em qualidade produtiva e eficiência. Agrupar inovações de marketing com inovações organizacionais seria também problemático porque algumas práticas de marketing não se ajustam a conceitos de mudanças organizacionais e porque diluiria bastante os dados em inovações organizacionais, levando a uma difícil interpretação dos resultados (OCDE, 2005, p. 18).

De forma análoga à dificuldade de classificação de inovações entre produto e marketing, a classificação de tipos de inovação em processo e produto pode gerar discussões específicas em serviços. Num produto tangível, a distinção sobre o que é inovação produto e processo é relativamente simples, uma vez que uma inovação de processo pode não alterar o produto em si. Um exemplo dessa constatação seria a produção de um artefato plástico manufaturado por um inovador processo de injeção plástica. O artefato produzido é rigorosamente o mesmo, o que é inovador é o processo de produção que pode gerar economia de energia elétrica ou menor desperdício para a empresa produtora desse bem tangível. O processo é inovador, não o produto.

Mas no setor de serviços, devido à propriedade de simultaneidade entre produção e consumo, qualquer alteração no processo básico de prestação do serviço provavelmente acabará impactando no serviço em si. É difícil e complexa a distinção sobre o que é de fato inovação de produto (o serviço em si) ou inovação de processo, tornando-se essa definição algo questionável.

Além disso, a classificação entre inovação tecnológica/não tecnológica pode igualmente gerar controvérsias. A própria palavra tecnologia traz complicadores para o estudo da inovação em serviços. Ela transmite uma ideia de que a inovação em serviços ocorre somente com adição de algum componente tecnológico num ambiente "high-tech" ou mesmo por meio da adição de uma nova tecnologia de informação na prestação do serviço.

Quadro 1. Tipos de inovação segundo o Manual de Oslo.

\begin{tabular}{|c|c|}
\hline Tipo & Definição \\
\hline Produto & $\begin{array}{c}\text { Uma inovação de produto é a introdução de um bem ou serviço novo ou significativamente } \\
\text { melhorado no que se refere a suas características ou a seus usos previstos. Isso inclui } \\
\text { melhoramentos expressivos nas especificações técnicas, componentes e materiais, } \\
\text { softwares incorporados, facilidade de uso ou outras características funcionais. }\end{array}$ \\
Implementação de métodos de produção ou distribuição novos ou \\
significativamente melhorados. Isso inclui mudanças significativas \\
nas técnicas, equipamentos e/ou softwares. \\
Marketing \\
É a implementação de um novo método de marketing envolvendo mudanças \\
significativas na concepção ou na embalagem do produto, no posicionamento \\
do produto, na promoção do produto ou na formação de preços. \\
Consiste na implementação de um novo método organizacional nas práticas \\
de negócios da empresa, na organização do local de trabalho ou nas relações externas. \\
\hline
\end{tabular}

Fonte: OCDE (2005). 
Mas as inovações não tecnológicas não seriam de igual ou maior relevância em serviços? Tome-se com exemplo a empresa prestadora de serviços Porto Seguro no Brasil. Ela inovou em seu segmento de mercado lançando um produto (seguro de automóveis) que possibilita ao usuário a utilização de uma equipe de funcionários da empresa dedicados a efetuar pequenos reparos domésticos em suas residências. Trata-se da adição de um serviço periférico (os reparos domésticos) a um serviço central (o seguro de automóveis). Essa inovação trouxe um benefício indiscutível para o usuário, sendo que, provavelmente, nada tem de tecnológica.

Ao mesmo tempo em que as classificações propostas pelo Manual de Oslo são de aplicação bastante restrita para o setor de serviços, faz-se necessária uma definição sobre o que se está denominando inovação em serviços neste trabalho. Uma possível abordagem é a conexão da percepção do usuário final com a inovação, seja ela de caráter incremental ou radical. Propõe-se neste artigo, partindo-se de conceitos e definições anteriormente apresentados, a seguinte definição sobre inovação em serviços:

\section{É a introdução de uma característica ou um conjunto de características (tecnológicas ou não tecnológicas) que propiciem a prestação de um serviço para o usuário final de uma nova maneira, ou de uma maneira melhorada. O usuário final deve reconhecer que o conjunto dessas características seja traduzido como benefício e tenha impacto em sua avaliação da prestação do serviço.}

Não é difícil enquadrar os exemplos de serviços citados nos parágrafos anteriores (o seguro residencial associado a reparos domésticos; pacote de serviços de internet banda larga, provedor e televisão por assinatura) dentro da definição apresentada. Entretanto, algumas inovações organizacionais puras, tais como a utilização de um novo sistema de bonificação para vendedores de seguros, estariam fora da classificação proposta, já que não seriam percebidas pelos consumidores finais.

Inovações que não resultem em benefícios diretos para os usuários finais da prestação do serviço fazem parte de outra categoria de inovação que não será o foco deste trabalho.

\subsection{Por que focar o estudo de inovações em serviços?}

Conforme apontado por Miles (2007), o estudo de inovações em serviços é um campo relativamente novo. Segundo esse autor, é frequente a abordagem do processo inovativo de uma empresa produtora de bens, mas nem tanto de trabalhos acadêmicos que abordam o tema de inovação em serviços como seu tema central. Ainda não está claro como as organizações de serviço inovam, apesar de alguns artigos tentarem explicar o fenômeno, tais como o de Barras (1985), de Gallouj e Weinsten (1997) ou de Bilderbeek et al. (1998).

É importante lembrar que a área de gestão de operações vem ultimamente focando a área de serviços muitas vezes adaptando as ferramentas e técnicas tradicionais oriundas da área da manufatura. Essa estratégia adaptativa pode funcionar adequadamente para alguns temas na área de manufatura e serviços, tais como gestão de estoques, gerenciamento de capacidade ou programas de qualidade. Entretanto pode se revelar uma armadilha quando o tema é a inovação, dada a natureza peculiar que o processo de projeto e gestão da operação de serviços possui (TIDD; HULL, 2005).

Bernardes e Bessa (2007) chamaram particularmente a atenção para alguns detalhes das diferenças entre inovação em serviços e de produtos a fim de tratá-los de forma diferenciada. Uma dessas singularidades está na forma estruturada com que a indústria realiza a inovação por meio de indicadores que retratem a aplicação de atividades tradicionais de Pesquisa e Desenvolvimento (P\&D), enquanto o setor de serviços não tem essa tônica. Isso pode ser visualizado na Tabela 1 .

Conforme a Tabela 1, há uma diferença substancial entre empresas de serviços e de manufatura no que diz respeito à posse e aplicação de atividades de $\mathrm{P} \& \mathrm{D}$. As empresas de serviços realizam a atividade de P\&D em menor intensidade se comparadas às empresas de manufatura, além de não possuírem laboratórios para pesquisa e desenvolvimento. Esses fatos contribuem para justificar a condução de pesquisas que busquem uma melhor compreensão da maneira como as empresas de serviço inovam e estão estruturadas, como proposto no presente trabalho.

Tabela 1. Indicadores das atividades de inovação, $P \& D$ e patentes para indústria e serviços.

\begin{tabular}{lcc}
\hline \multicolumn{1}{c}{ Atividades de Pesquisa e Desenvolvimento } & Indústria & Serviços \\
\hline Introduziram produto e/ou processo novo para o mercado nacional & $7,1 \%$ & $5,6 \%$ \\
Realizaram atividade de P\&D de forma sistemática ou contínua & $48,9 \%$ & $31,4 \%$ \\
Contratam atividade de P \& D & $25,6 \%$ & $30,4 \%$ \\
Possuem laboratórios de P \& D & $39,2 \%$ & $15,5 \%$ \\
Solicitaram registro de patentes/copyright & $55,3 \%$ & $25,2 \%$ \\
\hline
\end{tabular}

Fonte: Fundação SEADE. Pesquisa da Atividade Econômica Paulista - PAEP (2001). 
Kubota (2006) abordou as particularidades dos processos inovativos nos serviços e na manufatura. Conforme as palavras do autor:

A literatura sobre inovação em serviços é bastante convergente em suas principais propostas. Os principais autores defendem que o setor de serviços é inovativo, apesar das inovações apresentarem, em geral, caráter menos tecnológico, comparando-se com o que se observa na indústria... Ainda não existe um modelo conceitual que seja amplamente aceito na explicação do fenômeno (KUBOTA, 2009, p. 35).

\subsection{Algumas referências que podem ajudar na compreensão do fenômeno da inovação}

Talvez uma das referências mais difundidas na literatura que pode ser empregada para tentar explicar o fenômeno da inovação denomina-se Stage-Gates, apresentada por Cooper (1993), muito embora, originalmente ela tenha sido concebida para explicar os Processos de Desenvolvimento de Produtos. Nesta referência, há diversos pontos de decisão "passa - não passa" para a continuidade de um projeto de inovação, conforme apresentado na Figura 1.

Uma visão complementar para o desenvolvimento da inovação é apresentada por Hansen e Birkinshaw (2007). Estes autores propuseram o conceito da cadeia de valor da inovação, segundo o qual, embora o processo de desenvolvimento da inovação seja importante, há também outras etapas que devem ser igualmente consideradas. A partir de uma visão expandida, forma-se uma espécie de cadeia composta pelas seguintes fases: geração de ideias (intradepartamental, interdepartamental e interinstitucional); a conversão (seleção de ideias, incluindo a triagem, o financiamento e o desenvolvimento); e a difusão (que é a disseminação na organização e no mercado). A Figura 2 representa a cadeia da inovação apresentada por estes autores.

A linha de raciocínio seguida por Hansen e Birkinshaw (2007) é identificar em qual destas fases reside o gargalo da empresa no processo inovativo para que seja possível atuar para reduzi-lo. A ideia

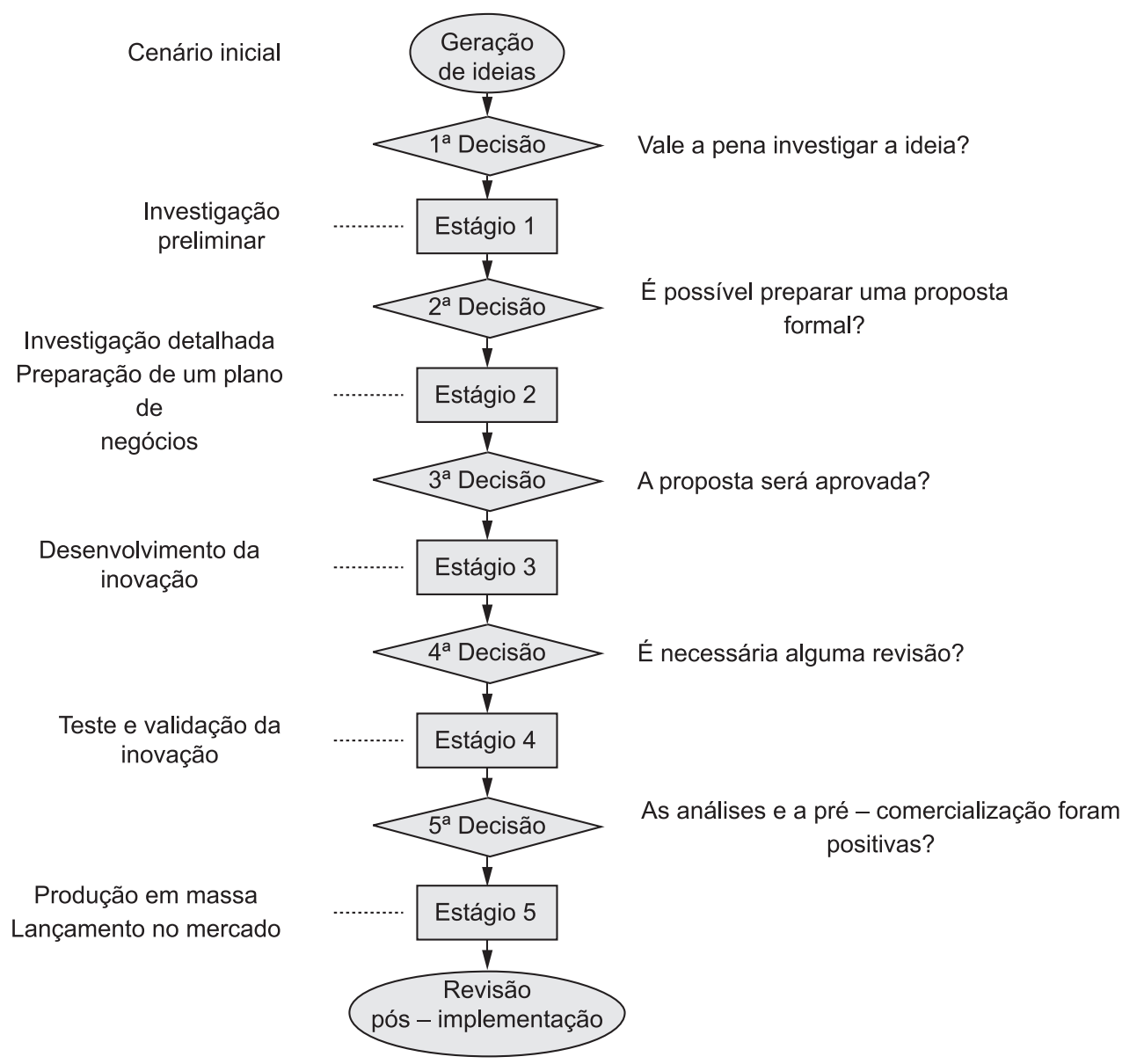

Figura 1. Estrutura Stage-Gate para o desenvolvimento de produtos. Fonte: adaptado de Cooper (1993). 


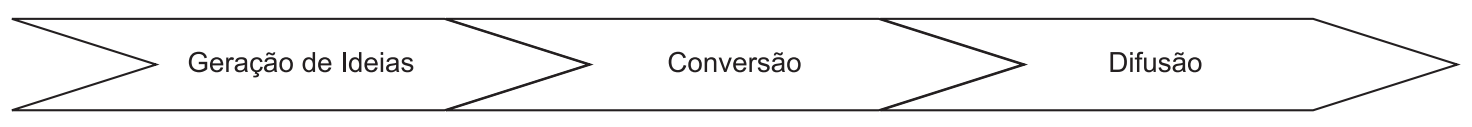

Exemplos de perguntas para cada fase da cadeia da inovação

\begin{tabular}{|c|c|c|}
\hline $\begin{array}{l}\text { Quais são as fontes de } \\
\text { geração de ideias(internas } \\
\text { e externas) empregadas } \\
\text { pela empresa? } \\
\text { Qual é a importância } \\
\text { relativa de cada fonte? } \\
\text { Como estas fontes podem } \\
\text { ser estimuladas? }\end{array}$ & $\begin{array}{l}\text { Como a ideia da inovação é } \\
\text { escolhida para se transformar em } \\
\text { inovação? Quais são os critérios } \\
\text { empregados? } \\
\text { Quais as áreas participantes do } \\
\text { processo de inovação? Qual é o } \\
\text { papel de cada área? } \\
\text { Como é o processo de } \\
\text { desenvolvimento? } \\
\text { Como a inovação é financiada pela } \\
\text { empresa? } \\
\text { Que recursos (estruturais e } \\
\text { financeiros) a ideia consumiu antes } \\
\text { de ser transformada em inovação? } \\
\text { Há testes/validações da inovação } \\
\text { no mercado? }\end{array}$ & $\begin{array}{l}\text { Como ocorreu o lançamento } \\
\text { da inovação no mercado? } \\
\text { Como ela foi comunicada } \\
\text { internamente (funcionários) e } \\
\text { externamente (para os } \\
\text { consumidores)? }\end{array}$ \\
\hline
\end{tabular}

Figura 2. A cadeia da inovação. Fonte: adaptado de Hansen e Birkinshaw (2007).

da cadeia da inovação guarda, desta forma, certa semelhança com a Teoria das Restrições apresentada por Goldratt (1993). Para exemplificar, pode haver empresas com muitas ideias, mas dificuldade de selecioná-las ou operacionalizá-las. Se essas empresas investirem pesadamente em outra fase da cadeia, como a conversão, suas ações poderão ser pouco eficazes na cadeia da inovação da empresa.

No trabalho de Sundbo e Gallouj (1998), é apresentando um conjunto de forças que contribuem com a inovação e agem interna e externamente à organização. Essas forças que compõem a estrutura proposta pelos autores podem incentivar ou podem representar obstáculos para o processo de inovação, classificadas em externas e internas.

As forças externas são as trajetórias (divididas em profissional, gerencial, tecnológica, institucional, social) e os atores, que se dividem em clientes, competidores, governo e fornecedores. As forças internas são representadas pela administração e estratégia, Setor de Inovação e recursos humanos.

De um modo geral, as trajetórias são ideias e lógicas difundidas por meio do sistema social e são forças que atuam externamente. Sundbo e Gallouj (1998) dividiram as trajetórias em:
- Trajetórias profissionais: são os métodos, conhecimentos e regras comportamentais existentes nos diferentes serviços;

- Trajetórias tecnológicas: compreendem novos usos de tecnologias que influenciam produtos e processos, como a internet e outras tecnologias de informação e conhecimentos;

- Trajetórias gerenciais: são ideias para novas formas organizacionais, tais como sistemas de motivação e reengenharia de processos de negócio;

- Trajetórias institucionais: relatam as tendências gerais de evolução e regulamentações das instituições políticas. Os autores consideram mudanças econômicas e programa de pesquisa como exemplos dessa trajetória;

- Trajetórias sociais: mostram a evolução de regras e convenções sociais. Como exemplo, os autores sugerem a consciência ambiental e ecológica.

As outras forças externas que levam à inovação são denominadas por Sundbo e Gallouj (1998) como atores. São pessoas, empresas ou organizações, cujos comportamentos afetam as possibilidades da empresa vender seus serviços, e, consequentemente, 
têm influência nas atividades de inovação. As forças externas são divididas em:

- Clientes: são os atores de maior importância, devido à intensidade do relacionamento com a empresa prestadora de serviços;

- Competidores: a competição torna esses atores uma força importante. Apesar das empresas competirem fundamentalmente entre si ao oferecerem os mesmos serviços, em alguns casos, pode também haver uma ação no sentido de cooperação entre elas. Esse duplo processo de concorrência/cooperação pode contribuir para o processo de inovação;

- Governo: representa um ator com uma multiplicidade de papéis; pode ser visto como um cliente, um fornecedor ou até mesmo um competidor;

- Fornecedores: é a última força externa; possui maior ou menor importância de acordo com o setor de serviço considerado.

Sundbo e Gallouj (1998) consideram que a administração e a estratégia, o Setor de Inovação e a área de recursos humanos fazem parte das forças internas impulsionadoras do processo de inovação em serviços.

A administração da empresa, frequentemente, apresenta uma estratégia ou uma ideia sobre qual direção seguir e esta seria o que os autores chamam de força atuante interna administração e estratégia.
Para Sundbo e Gallouj (1998), a força Setor de Inovação é representada pela existência de um departamento de pesquisa e desenvolvimento (P\&D), cuja função é introduzir e coletar ideias, ou seja, ser agente de inovação.

A força interna dos recursos humanos inclui todos os profissionais em todos os níveis, afinal são eles que se envolvem no processo de inovação da empresa.

A Figura 3 retrata a estrutura proposta por Sundbo e Gallouj (1998) para descrever as forças explicitadas acima no processo de inovação em serviços.

É possível traçar um paralelo entre a estrutura de forças atuantes nas inovações em serviços com o conceito de inovação aberta (open innovation) defendido por Chesbrough (2006).

Para Chesbrough (2006), nos modelos tradicionais de inovação, as vantagens competitivas seriam alcançadas por meio de investimentos em grandes laboratórios de $\mathrm{P} \& \mathrm{D}$, sendo grande parte da pesquisa desenvolvida internamente na empresa. $\mathrm{O}$ autor propõe uma mudança nessa constatação, ao apresentar o conceito de Open Innovation, ou seja, a busca da inovação por meio de caminhos internos ou externos para avançar no desenvolvimento de novas tecnologias.

De acordo com Chesbrough (2006), em 1971, as empresas com mais de 25 mil empregados eram responsáveis por $70,7 \%$ do valor das inovações no mercado, mas despencaram para 40,9\% em 2003. Por outro lado, as pequenas empresas, com menos de mil empregados, subiram de $4,4 \%$ para os atuais $22,5 \%$. Uma das razões para essa assimetria, para o autor, é a nova forma adaptativa de lidar com a inovação

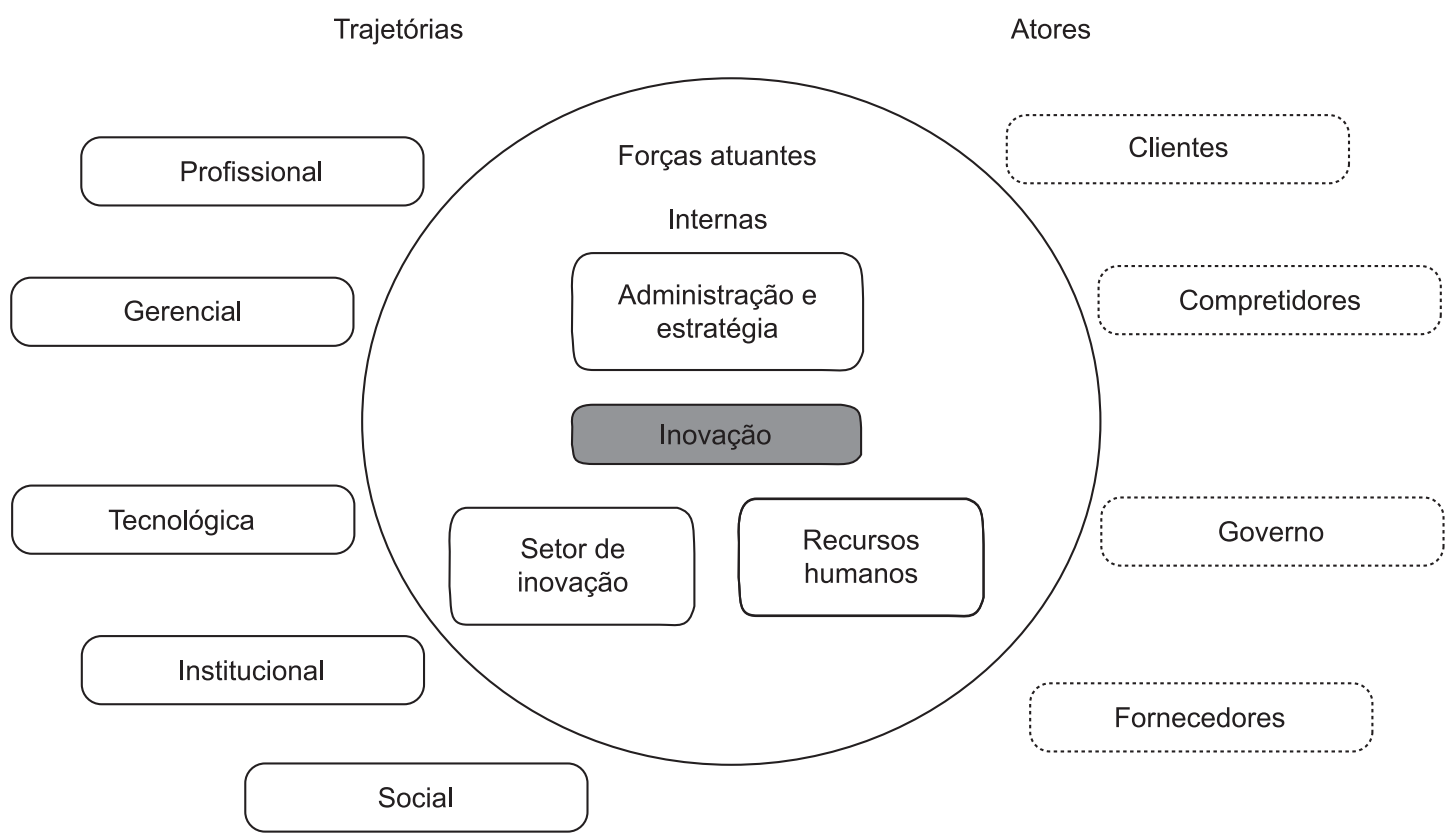

Figura 3. Estrutura de forças atuantes nas inovações em serviços. Fonte: baseado em Sundbo e Gallouj (1998). 
das pequenas empresas. Com recursos escassos para investir na pesquisa e desenvolvimento cativos, elas podem empregar contratos e parcerias externas para auxiliar o processo inovativo.

A linha de raciocínio da inovação aberta defendida por Chesbrough (2006) e da estrutura de fontes de inovação apresentada por Sundbo e Gallouj (1998) são convergentes no sentido de que uma empresa deve buscar fontes alternativas (internas ou externas) para contribuir com o seu processo inovativo. Na inovação aberta, a ideia central é que em um mundo com informações amplamente disseminadas, as empresas podem inclusive comprar ou licenciar processos de inovação (como patentes) de outras empresas. Além disso, as invenções internas que não forem usadas pelos negócios da própria empresa devem ser externalizadas, de forma que outras empresas tenham a oportunidade de utilizá-las sob uma licença, por exemplo.

No setor de serviços, um dos exemplos de aplicação da ideia de inovação aberta, defendido por Chesbrough pode ser visualizado na iniciativa da rede norte americana de cafeterias Starbucks, denominada My Starbucks Idea (http://mystarbucksidea.force. $\mathrm{com} /$ ). Trata-se de uma ferramenta que permite que qualquer pessoa ofereça ideias, vote e faça comentários por meio do site da empresa, sendo que as melhores iniciativas podem ajudar a redefinir o próprio futuro da empresa. Trata-se do envolvimento direto de uma fonte externa à empresa para auxiliar no processo inovativo.

Poder-se-ia argumentar que a rede Starbucks encontrou apenas uma forma de utilizar um contact center (uma espécie de Call Center com interação via chat ou troca de mensagens) para atuar no processo da inovação. Mas a ideia é mais ampla, muito próxima do desenvolvimento compartilhado defendido por Vermeulen e Van der Aa (2005). Há, neste caso, uma estrutura específica da empresa responsável por classificar, filtrar, encaminhar e viabilizar a ideia em produtos ou serviços inovadores.

Para ilustrar este ponto, as ideias sugeridas pelos internautas são divididas em três categorias: produtos, experiência e envolvimento (com a sociedade). Cada ideia é analisada por uma equipe designada pela Starbucks, chamada de Idea Partners. No site da empresa, pode-se inclusive acompanhar algumas ideias que estão sob revisão, o que pode significar estar muito próximo da implementação.

A iniciativa da rede norte-americana já apresenta resultados positivos. Uma das ideias que surgiu foi o Splash Stick, uma espécie de tampa para evitar que as pessoas mais apressadas ou que levam o café no carro derramem o produto. É possível que a Starbucks acabe conquistando os seus clientes por meio do engajamento no processo de inovação da empresa, provavelmente com um custo muito abaixo do valor dos benefícios obtidos pela geração da inovação.

Outro exemplo de aplicação de inovação aberta pode ser encontrado na IBM. A fim de agilizar o processo inovativo, a IBM promove encontros para ouvir os familiares de seus funcionários sobre novas ideias para a companhia. Chesbrough (2006) também relata o episódio em que a IBM abriu mão da proteção de muitas de suas patentes em busca da ampliação do uso das tecnologias que desenvolve a partir das sugestões dos usuários.

Dentro da política de inovação aberta da IBM, também está seu apoio ao desenvolvimento do Linux, sistema operacional concorrente do Microsoft Windows, programado em código aberto, não proprietário, de forma que os programadores que aperfeiçoam o sistema não recebem royalties, só o reconhecimento pela inovação.

Uma análise mais crítica poderia argumentar que há pouca novidade no discurso de Chesbrough. Vários autores, inclusive Sundbo e Gallouj (1998), já chamavam a atenção para a utilização de fontes alternativas de inovação. Mas um ponto de mérito para Chesbrough foi conseguir chamar a atenção das empresas, fazendo com que elas repensassem sua estrutura para o processo inovativo.

Há dois fatos que podem diferenciar a iniciativa da Starbucks da tradicional "caixinha de sugestões" já implementada há décadas por muitas empresas. Primeiro, trata-se de uma iniciativa estratégica da empresa em que se busca a aproximação e envolvimento do cliente por meio de uma nova via: a internet; segundo, a empresa preparou uma estrutura interna, com equipes específicas destinadas a essa finalidade, de modo a permitir que as sugestões fluíssem até se tornarem inovações. É possível que esses fatores não constituam uma novidade propriamente dita para muitas empresas, mas há um mérito neste caso de se lançar luzes para processos inovativos que incluam de uma forma sistemática fontes alternativas de inovação, reduzindo o peso relativo da área de pesquisa e desenvolvimento dessas empresas.

Tanto a iniciativa da Starbucks quanto a da Linux podem fornecer pistas sobre como pode ocorrer o processo inovativo em empresas prestadoras de serviços, bem como sobre as diferenças que este processo possui em relação às empresas de manufatura.

Apresentadas e discutidas as principais referências teóricas sobre o tema de inovação em serviços (do ponto de vista de sua gestão), passar-se-á agora às questões das escolhas metodológicas feitas ao longo da pesquisa que gerou este artigo.

\section{Procedimentos metodológicos}

O tema do presente trabalho está relacionado a uma melhor compreensão do processo de inovação 
nas empresas de serviço. A questão norteadora do trabalho é: Como ocorrem as inovações neste setor? Trata-se de um trabalho exploratório de um tema ainda incipiente na literatura, tornando uma abordagem predominantemente quantitativa de difícil aplicação.

O caráter exploratório dessa pesquisa decorre do fato de que as informações e conclusões obtidas fornecerão elementos para uma melhor compreensão sobre como as empresas de serviço inovam, levando-se em conta aspectos como a presença de um setor específico de inovação nas empresas, o processo de geração de ideias, de conversão das ideias na inovação e a difusão interna e externa da inovação.

Dessa maneira, o presente trabalho se caracterizou por ser um estudo qualitativo e exploratório e, como consequência, não teve a preocupação de formular conclusões generalizantes. Os instrumentos de pesquisa utilizados para a realização do trabalho foram a pesquisa bibliográfica e o estudo de casos múltiplos.

\subsection{As proposições da pesquisa}

Vale lembrar que uma das características do estudo de caso não é formalmente o de testar hipóteses. Todavia uma possível alternativa é lidarmos com proposições que podem ser formuladas com a finalidade de garantir que a realização da pesquisa permaneça focada em seus objetivos principais e não se transforme numa ampla coleta de dados sem direção. São duas proposições as que norteiam o presente trabalho, a saber:

P1: As empresas de serviços estudadas possuem uma lógica estruturada para desenvolvimento da inovação, tal como a lógica Stage-Gates apresentada por Cooper (1993) para o setor de produtos.

P2: O padrão de inovação em serviços das empresas estudadas apresenta características similares aos dos sistemas "abertos", tal como proposto por Chesbrough (2006).

\subsection{Os critérios de seleção: a escolha das empresas estudadas e dos respondentes}

Como apontado por Yin (2005) em estudos de casos, a empresa estudada não é escolhida ao acaso. É preferível que ela seja selecionada intencionalmente para explorar os objetos de estudo contidos nas questões da pesquisa. A evolução do conhecimento do fenômeno dependerá da correta escolha do(s) caso(s) (SOUZA; VOSS, 2001).

Um ponto importante para a escolha do tipo de serviço e de empresa estudados na pesquisa efetuada foi o estabelecimento do usuário final do serviço como uma pessoa física. Essa escolha foi derivada da definição de inovação proposta neste trabalho, definição esta que parte da percepção do consumidor do serviço sobre os benefícios propiciados pela inovação. Dessa forma, estavam descartados alguns serviços intensivos em conhecimento, como assessorias em informática ou consultorias jurídicas que prestam serviços para outras empresas. O critério das empresas potenciais a serem estudadas foi o de ser uma empresa do tipo B2C (business to consumer).

O segundo critério para a seleção das empresas que seriam estudadas foi focar num setor inovador de serviços, já que um dos objetivos do trabalho era justamente uma melhor compreensão do processo inovativo nessas empresas. A questão passou a ser então como definir se um setor de serviços é inovador.

Um caminho para contornar essa questão foi considerar a pesquisa produzida pela Fundação SEADE denominada PAEP (Pesquisa sobre a atividade econômica paulista) em 2001. Embora os critérios para inovação adotados pela pesquisa se referissem apenas à inovação tecnológica e desconsiderassem as inovações de processo ou de mercado, julgou-se que poderiam também ser apropriadas para o setor de serviços e, portanto, esta pesquisa foi utilizada como referência.

Pelo critério da PAEP, considera-se uma empresa inovadora aquela empresa que efetivamente tenha introduzido um produto (bem ou serviço) tecnologicamente novo ou significativamente aperfeiçoado para o mercado nacional. Esse critério seguiu as recomendações do Manual de Oslo, e foi aplicado tanto para o caso da manufatura, como para serviços. Para esse último, os respondentes do questionário da pesquisa da PAEP foram empresas com mais de vinte pessoas ocupadas, e a população envolvida foi de mais de 21 mil empresas localizadas no Estado de São Paulo. A Tabela 2 apresenta uma síntese dos resultados da PAEP de 2001 para o setor de serviços.

Pela Tabela 2, as empresas de serviços que mais introduziram serviço ou produto tecnologicamente novo ou significativamente aperfeiçoado para o mercado nacional foram as empresas relacionadas a Atividades de Informática e de Telecomunicações, com taxas de inovação de respectivamente $29,73 \%$ e $14,88 \%$. O passo seguinte para a escolha das empresas estudadas foi um maior detalhamento sobre que tipos de empresas faziam parte desses dois grupos.

As possíveis empresas nas quais os casos poderiam ser estudados, além de serem empresas teoricamente inovadoras (já que apresentavam a maior taxa de inovação setorial, como apresentado no Quadro 1), deveriam ser empresas que prestavam serviços diretamente a uma pessoa física $(B 2 C)$. Enquadravam-se nessas classificações empresas dos seguintes setores:

- Telecomunicações: empresas de telefonia fixa comutada, telefonia móvel celular, e as operadoras de televisão por assinatura; 
Tabela 2. Empresas de serviços que introduziram serviço ou produto tecnologicamente novo ou significativamente aperfeiçoado para o mercado nacional.

\begin{tabular}{lrccc}
\hline \multicolumn{1}{c}{ Atividades } & Total & Empresas inovadoras & Taxa de inovação (\%) & Ranking \\
\hline Total & $\mathbf{2 0 . 6 7 1}$ & $\mathbf{9 2 3}$ & $\mathbf{4 , 4 7}$ & \\
Ativ. Informática & 962 & 286 & 29,73 & 1 \\
Telecomunicações & 121 & 18 & 14,88 & 2 \\
Saúde & 1.434 & 104 & 7,25 & 3 \\
Limp. Urbana/Esgoto & 89 & 6 & 6,74 & 4 \\
Ativ. Imobiliárias & 1.069 & 60 & 5,61 & 5 \\
Correio & 107 & 6 & 5,61 & 6 \\
Ativ. Lazer/Cultura & 1.315 & 70 & 5,32 & 7 \\
Educação Não Formal & 303 & 16 & 5,28 & 8 \\
Serv. Técnicos às Empresas & 1.845 & 94 & 5,09 & 9 \\
Energia, Gás e Água & 268 & 13 & 4,85 & 10 \\
Educação Formal & 1.703 & 68 & 3,99 & 11 \\
Serv. Agricultura & 190 & 6 & 3,16 & 12 \\
Serviços Pessoais, Ativ. & 2.036 & 56 & 2,75 & 13 \\
Assistenciais e Coletivas e Outros & & & & 14 \\
Transporte & 2.761 & 64 & 2,32 & 15 \\
Serv. Aux. às Empresas & 3.200 & 48 & 1,50 & 16 \\
Alojamento & 796 & 4 & 0,50 & 17 \\
Alimentação & 2.472 & 2 & 0,08 & \\
\hline
\end{tabular}

Fonte: Fundação SEADE. Pesquisa da Atividade Econômica Paulista - PAEP (2001).

- Atividades de Informática: empresas pertencentes à divisão de portais, provedores de conteúdo e acesso e outros serviços de informação na internet.

Após o emprego destes dois filtros para a seleção das empresas, foram selecionadas as empresas e realizados cinco estudos de casos, conforme mostra a Tabela 3.

\subsection{A coleta e tratamento de dados}

As técnicas utilizadas para a realização do estudo de caso foram: observação in loco, análise de relatórios e documentos e, principalmente, entrevistas realizadas com os executivos da empresa. O uso de múltiplas fontes de obtenção de dados, segundo Yin (2005), constitui a técnica denominada triangulação. Segundo o autor, a triangulação possibilita examinar diferentes evidências que são acumuladas ao longo de entrevistas com diferentes fontes que qualificam os casos.

Seguindo ainda a orientação de Yin (2005), as entrevistas foram realizadas segundo roteiros básicos de pesquisa, sem porém perder a necessária flexibilidade para que fossem feitas perguntas complementares, e sem que fosse restringida a liberdade dos entrevistados opinarem sobre os temas abordados. Foi pedido, a certa altura da entrevista, que o entrevistado identificasse uma inovação relevante ocorrida nos últimos cinco anos; esta inovação foi mapeada do ponto de vista das fases da cadeia de valor expandida, proposta por Hansen e Birkinshaw (2007).

O tratamento dos dados foi realizado após a execução de cada entrevista, quer dizer, com perguntas pré-estabelecidas respondidas e gravadas em formato digital, o passo seguinte consistiu em escutar repetidamente e com atenção as gravações, e desta forma, transcrever as palavras dos entrevistados. No total, os pesquisadores transcreveram novecentos minutos de gravações, resultando num volume de informações de cento e setenta páginas.

Segundo recomendação de Yin (2005) e Bardin (2000), para a apresentação e comparabilidade dos dados obtidos em cada caso, foi preparado um conjunto de categorias de análise para dispor as evidências coletadas. Essas categorias de análise derivaram dos roteiros de pesquisa aplicados. Como exemplos de categorias de análises desenvolvidas pelos autores destacaram-se: i) exemplos de inovações em serviços; ii) estrutura da empresa para a inovação; iii) detalhamento do processo da inovação rastreada.

A preparação das categorias de análise é uma das técnicas de pesquisa denominada análise de conteúdo. Segundo Malhorta (2004), a análise de conteúdo possibilitou interpretar e fazer uma leitura adequada e dinâmica das questões colocadas nas entrevistas. Ela foi particularmente útil neste trabalho por permitir que os dados obtidos das transcrições das gravações 
Tabela 3. Caracterização das empresas estudadas nos estudos de caso.

\begin{tabular}{|c|c|c|c|c|c|}
\hline Empresa & Serviço oferecidos & $\begin{array}{l}\mathrm{N}^{\circ} \text { aproximado } \\
\text { de clientes }\end{array}$ & $\begin{array}{c}\mathrm{N}^{0} \text { de } \\
\text { funcionários }\end{array}$ & $\begin{array}{l}\text { Faturamento } \\
\text { aproximado } \\
\text { em } 2008\end{array}$ & $\begin{array}{c}\text { Relação } \\
\text { faturamento } \\
\text { por cliente }\end{array}$ \\
\hline Beta & $\begin{array}{c}\text { Telefonia Celular; } \\
\text { Rádio; Acesso à Internet }\end{array}$ & 2 milhões & 4.000 & $\mathrm{R} \$ 1$ bilhão & 500 \\
\hline Gama & $\begin{array}{c}\text { Telefonia Fixa e } \\
\text { Acesso a Internet } \\
\text { (banda larga e acesso discado) }\end{array}$ & 48 milhões* & 20.000 & $\mathrm{R} \$ 8,2$ bilhões & 171 \\
\hline Delta & $\begin{array}{l}\text { Provedor de Internet; } \\
\text { Site de Conteúdo }\end{array}$ & 1,74 milhões & 2.400 & R\$ 802 milhões & 461 \\
\hline Kappa & $\begin{array}{l}\text { Telefonia Celular; } \\
\text { Acesso à Internet }\end{array}$ & 46 milhões & 5.300 & $\mathrm{R} \$ 3,8$ bilhões & 83 \\
\hline Zetha & $\begin{array}{c}\text { TV por assinatura; } \\
\text { Acesso à Internet (Banda Larga) } \\
\text { e Telefonia Fixa }\end{array}$ & 8,10 milhões** & 4.500 & $\mathrm{R} \$ 2$ bilhões & 247 \\
\hline
\end{tabular}

fossem ordenados e interpretados para formulação de premissas analíticas sobre as variáveis de análise.

\subsection{A validação dos casos}

Depois de redigidos os casos individualmente, o pesquisador os enviou por $e$-mail para os profissionais entrevistados de maior nível hierárquico de cada empresa. Dessa forma, se numa empresa foram entrevistados um supervisor, um gerente e um diretor, os dados consolidados das três entrevistas foram destinados ao nível de diretoria. Objetivou-se com esse procedimento corrigir possíveis equívocos obtidos nas informações coletadas nos casos, além de propiciar uma visão ampla sobre quais informações seriam utilizadas pelo pesquisador no trabalho.

Ficou acertado entre o pesquisador e os entrevistados que os nomes das empresas estudadas, bem como os nomes dos entrevistados não estariam explícitos neste trabalho.

\section{Apresentação e discussão dos resultados}

\subsection{Exemplos de inovações em serviços encontradas nos casos}

O Quadro 2 sintetiza as inovações encontradas pelo pesquisador nos casos estudados, bem como a origem e os benefícios gerados para os usuários da inovação escolhida em cada empresa para aprofundamento ao longo da entrevista, conforme definição proposta no item 1.1 .

Analisando-se o conjunto das inovações pesquisadas nos casos, é fácil perceber o forte viés tecnológico encontrado nas inovações estudadas. Casos como o Sistema de Reconhecimento de Voz, o Controle Remoto Infantil, ou o Localizador de Frotas somente foram possíveis de serem levados a cabo graças ao uso intensivo de tecnologia.

Embora o pesquisador tenha sempre tomado cuidado para não induzir os entrevistados a responder sob esse ponto de vista (jamais citando a palavra inovação tecnológica durante as entrevistas), a questão da tecnologia permeou todas as inovações encontradas. Mesmo no caso da inovação do "empacotamento" dos serviços de TV por assinatura, internet banda larga e telefone fixo apresentado pela empresa Zetha, o que poderia ser interpretado inicialmente como uma inovação de marketing segundo a OCDE (2005), também foi, na realidade, uma inovação tecnológica, já que foi a tecnologia que permitiu o oferecimento do chamado triple-play.

A possível causa deste viés foi a natureza dos serviços pesquisados. Conforme apresentado anteriormente, um dos critérios adotados pelos pesquisadores para selecionar os casos a serem pesquisados foi o de buscar empresas que fossem inovadoras em serviços, fato que direcionou os estudos para atividades de informática e telecomunicações, nas quais o componente tecnológico é determinante.

Esse fato complementa o que foi proposto por Sundbo e Gallouj (1998). Segundo esses autores, as inovações em serviços são, em sua maioria, adições de novos conhecimentos ou informações disponibilizadas para consumidores. A tecnologia pode ser encarada como o meio de adição, isto é, um "fio condutor" que possibilita que essas informações ou conhecimentos sejam incorporados aos serviços dessa natureza. Logo, não foi propriamente uma surpresa identificar que, para as atividades de informática e telecomunicações selecionadas, a vertente tecnológica florescesse nas inovações detalhadas nos casos. 
Quadro 2. Resumo das inovações investigadas na pesquisa.

\begin{tabular}{|c|c|c|c|}
\hline Empresa & Inovação & Origem & Benefícios aos consumidores \\
\hline \multirow[t]{3}{*}{ Beta } & $\begin{array}{l}\text { Comunicação } \\
\text { por ondas de } \\
\text { rádio acoplada ao } \\
\text { telefone celular. }\end{array}$ & $\begin{array}{l}\text { Sistema desenvolvido por empresa } \\
\text { parceira (tecnologia iDEN). Já } \\
\text { oferecido aos clientes desde o início } \\
\text { das operações no Brasil (1997). }\end{array}$ & $\begin{array}{l}\text { Possibilidade de conversação via rádio } \\
\text { sem limitações de tempo e sem tarifações } \\
\text { para todos os aparelhos telefônicos da } \\
\text { empresa no Brasil e exterior. }\end{array}$ \\
\hline & $\begin{array}{l}\text { Implementação } \\
\text { de URAs } \\
\text { (Unidades } \\
\text { de Respostas } \\
\text { Automáticas) }\end{array}$ & $\begin{array}{l}\text { Times de Trabalhos (QATs). } \\
\text { Solução encontrada para o problema } \\
\text { do aumento do tempo médio de } \\
\text { atendimento em virtude da expansão } \\
\text { do número de clientes. }\end{array}$ & $\begin{array}{l}\text { Informações mais ágeis, sem a } \\
\text { necessidade do usuário interagir com o } \\
\text { operador. Redução das filas para } \\
\text { atendimento nos horários de pico. }\end{array}$ \\
\hline & $\begin{array}{l}\text { Localizador } \\
\text { de Frotas }\end{array}$ & $\begin{array}{l}\text { Necessidade identificada pela área } \\
\text { de Produtos e Serviços. A demanda } \\
\text { partiu de um cliente específico } \\
\text { (empresa seguradora). }\end{array}$ & $\begin{array}{l}\text { Possibilidade de rastreamento do veículo } \\
\text { da frota da seguradora, além do traçado de } \\
\text { históricos de percursos. O sistema fornece } \\
\text { localização exata a cada cinco minutos. }\end{array}$ \\
\hline \multirow[t]{2}{*}{ Gama } & $\begin{array}{c}\text { Sistema de } \\
\text { Reconhecimento } \\
\text { de Voz }\end{array}$ & $\begin{array}{l}\text { Equiparação das operações de } \\
\text { atendimento com outros países } \\
\text { onde a empresa atua e necessidade } \\
\text { de melhoria operacional para } \\
\text { direcionamento das chamadas. }\end{array}$ & $\begin{array}{l}\text { Redução do tempo necessário para obtenção } \\
\text { das informações. O reconhecimento de voz } \\
\text { também direciona as chamadas para ilhas } \\
\text { de atendimento específicas, conforme a } \\
\text { necessidade específica dos usuários. }\end{array}$ \\
\hline & $\begin{array}{l}\text { Ilha de } \\
\text { Reiteração }\end{array}$ & $\begin{array}{l}\text { Ação conjunta entre as } \\
\text { vice-presidências jurídica e de } \\
\text { atendimento visando reduzir o } \\
\text { número de processos judiciais } \\
\text { pelos clientes. }\end{array}$ & $\begin{array}{l}\text { Maior possibilidade para uma solução efetiva } \\
\text { dos problemas dos usuários. Os operadores } \\
\text { entram em contato com os consumidores } \\
\text { após estes estabelecerem quatro contatos sem } \\
\text { obter sucesso na tratativa de problemas. }\end{array}$ \\
\hline \multirow[t]{2}{*}{ Delta } & $\begin{array}{l}\text { Serviço de } \\
\text { Rádio pela } \\
\text { Internet }\end{array}$ & $\begin{array}{l}\text { Iniciativa da presidência da } \\
\text { empresa há nove anos. }\end{array}$ & $\begin{array}{l}\text { Possibilidade do cliente ouvir músicas e } \\
\text { notícias e realizar downloads através do } \\
\text { computador em qualquer parte do mundo } \\
\text { com acesso à internet. }\end{array}$ \\
\hline & $\begin{array}{l}\text { Assistência } \\
\text { Técnica } \\
\text { Domiciliar }\end{array}$ & $\begin{array}{l}\text { Oportunidade identificada pela Área } \\
\text { de Atendimento que não conseguia } \\
\text { resolver todas as solicitações dos } \\
\text { clientes de forma remota (telefone } \\
\text { ou acesso remoto). Foi um trabalho } \\
\text { conjunto com o Setor de Inovação. }\end{array}$ & $\begin{array}{l}\text { Suporte total para usuários através de uma } \\
\text { equipe de técnicos especializados que pode } \\
\text { se deslocar para o domicílio do cliente com } \\
\text { agendamento de dia e horário. Os técnicos } \\
\text { são habilitados para solucionar uma ampla } \\
\text { gama de problemas (instalação de softwares } \\
\text { e hardwares, cabos, redes, etc). }\end{array}$ \\
\hline \multirow[t]{3}{*}{ Kappa } & $\begin{array}{l}\text { Ilha de } \\
\text { atendimento } \\
\text { específica para } \\
\text { usuários do } \\
\text { iPhone }\end{array}$ & $\begin{array}{l}\text { Iniciativa da presidência da empresa } \\
\text { que almejava um atendimento } \\
\text { diferenciado para esse segmento de } \\
\text { mercado (usuários do iPhone). }\end{array}$ & $\begin{array}{l}\text { Atendimento direto e pessoal, } \\
\text { ausência de URA, operadores mais } \\
\text { qualificados e com maior autonomia. }\end{array}$ \\
\hline & $\begin{array}{l}\text { Sistema de } \\
\text { Faturamento } \\
\text { Unificado }\end{array}$ & $\begin{array}{l}\text { Demanda interna da área do Call } \\
\text { Center para a área de sistemas. }\end{array}$ & $\begin{array}{l}\text { Usuários não precisavam ser transferidos } \\
\text { do atendimento básico para área de } \\
\text { faturamento para obtenção de informações } \\
\text { sobre valores das faturas. }\end{array}$ \\
\hline & $\begin{array}{l}\text { Utilização do } \\
\text { Windows Live } \\
\text { Messenger }\end{array}$ & $\begin{array}{l}\text { Proposta da Diretoria de } \\
\text { Marketing e Inovação. }\end{array}$ & $\begin{array}{l}\text { Possibilidade dos usuários } \\
\text { utilizarem o hotmail, o msn-messenger e } \\
\text { acessar o orkut via celular. }\end{array}$ \\
\hline \multirow[t]{3}{*}{ Zetha } & $\begin{array}{l}\text { Triple Play - TVs } \\
\text { por assinatura, } \\
\text { internet banda } \\
\text { larga e telefone } \\
\text { num só cabo. }\end{array}$ & $\begin{array}{l}\text { Replicação do modelo de uma } \\
\text { empresa similar norte-americana que } \\
\text { já operava dessa forma. }\end{array}$ & $\begin{array}{l}\text { Redução do valor pago } \\
\text { dos três serviços que formam } \\
\text { um pacote combinado. }\end{array}$ \\
\hline & $\begin{array}{l}\text { Banda Larga } \\
\text { Ultra-Rápida }\end{array}$ & $\begin{array}{l}\text { Benchmarking conduzido pela } \\
\text { área de Produtos e Serviços com } \\
\text { empresas similares de outros países. }\end{array}$ & $\begin{array}{l}\text { Conexão com a internet com uma velocidade } \\
\text { de até trezentos megabytes por segundo. }\end{array}$ \\
\hline & $\begin{array}{l}\text { Controle } \\
\text { Remoto } \\
\text { Infantil }\end{array}$ & $\begin{array}{c}\text { Aumento das reclamações } \\
\text { dos usuários pela alta complexidade } \\
\text { do novo controle remoto da } \\
\text { televisão digital. }\end{array}$ & $\begin{array}{l}\text { Simplificação do uso do aparelho de controle } \\
\text { remoto e limitação das possibilidades } \\
\text { para crianças selecionarem apenas canais } \\
\text { apropriados a esse público. }\end{array}$ \\
\hline
\end{tabular}




\subsection{A estrutura das empresas para a inovação}

Consoante ao que foi apontado por Marklund (2000) e Bernardes e Bessa (2007), as empresas estudadas, em sua maioria, não dispunham de uma estrutura exclusivamente formalizada e dedicada à inovação, de forma semelhante a empresas de produtos que possuem uma área dedicada para atividades de Pesquisa e Desenvolvimento. Ao invés disto, a inovação em serviços nas empresas estudadas normalmente é responsabilidade de áreas correlatas às funções de marketing. O Quadro 3 apresenta uma síntese de como as empresas estão estruturadas para a Inovação, bem como um breve descritivo de cada setor responsável pela gestão da inovação.

\subsection{O processo de inovação para as empresas de serviços}

A seguir, a partir das inovações estudadas, encontra-se uma síntese das etapas da Cadeia de Inovação conforme estrutura proposta por Hansen e Birkinshaw (2007).

\subsubsection{A geração da ideia}

O primeiro passo para descrever as maneiras pelas quais as empresas de serviços geraram ideias foi resgatar todas as possíveis formas pelas quais as ideias das inovações estudadas foram geradas, a saber:

a) Propostas do Setor de Inovação;

Quadro 3. Estrutura das empresas de serviço para a inovação.

\begin{tabular}{|c|c|c|c|c|}
\hline & $\begin{array}{l}\text { Denominação } \\
\text { interna do } \\
\text { setor de } \\
\text { inovação } \\
\end{array}$ & $\begin{array}{c}\mathbf{N}^{\circ} \text { de } \\
\text { pessoas }\end{array}$ & $\begin{array}{c}\text { Principal } \\
\text { executivo } \\
\text { da área/ } \\
\text { subordinação }\end{array}$ & Breve descritivo da área \\
\hline Beta & $\begin{array}{l}\text { Gerência } \\
\text { de Novos } \\
\text { Produtos e } \\
\text { Serviços }\end{array}$ & 15 & $\begin{array}{c}\text { Gerente de } \\
\text { Novos Produtos } \\
\text { e Serviços que } \\
\text { responde ao } \\
\text { Vice-Presidente de } \\
\text { Marketing }\end{array}$ & $\begin{array}{l}\text { A área coordena os lançamentos (controle de cronograma } \\
\text { e de custos) de novos produtos e serviços. Ela é responsável } \\
\text { pela análise inicial da viabilidade técnica, pelo estudo de } \\
\text { potencial de mercado e pela preparação de um plano de } \\
\text { negócios que é apresentado para outras áreas. }\end{array}$ \\
\hline Gama & $\begin{array}{l}\text { Diretoria de } \\
\text { Inovação } \\
\text { Estratégica }\end{array}$ & 30 & $\begin{array}{c}\text { Diretor de } \\
\text { Inovação } \\
\text { Estratégica que } \\
\text { responde ao } \\
\text { Vice-Presidente } \\
\text { Técnico }\end{array}$ & $\begin{array}{l}\text { A área é responsável pelos lançamentos de novos produtos } \\
\text { e serviços e também coordena a iniciativa da Incubadora } \\
\text { de Negócios. A Diretoria de Inovação Estratégica é } \\
\text { responsável pela elaboração de estudos de caso que são } \\
\text { apresentados para a Vice-Presidência Técnica. As demais } \\
\text { áreas não participam da decisão de continuidade dos casos } \\
\text { aprovados. A Área de Marketing é responsável pelo } \\
\text { "empacotamento" dos produtos (formação de preços). }\end{array}$ \\
\hline Delta & $\begin{array}{l}\text { Diretoria de } \\
\text { Portifólio } \\
\text { de Novos } \\
\text { Produtos }\end{array}$ & 17 & $\begin{array}{l}\text { Diretor de } \\
\text { Novos Produtos } \\
\text { e Negócios } \\
\text { subordinado ao } \\
\text { Diretor Geral }\end{array}$ & $\begin{array}{l}\text { É uma área relativamente nova na empresa, } \\
\text { foi criada em } 2007 \text { para contrabalançar a perda de } \\
\text { receita (gerada pelo fim da obrigatoriedade de } \\
\text { contratação de provedores). Ela coordena os lançamentos } \\
\text { (controle de cronograma e de custos) de novos produtos } \\
\text { e serviços e a preparação de um plano de negócios que é } \\
\text { apresentado para o board da empresa. }\end{array}$ \\
\hline Kappa & $\begin{array}{l}\text { Diretoria } \\
\text { de Novos } \\
\text { Produtos e } \\
\text { Serviços }\end{array}$ & 37 & $\begin{array}{c}\text { Diretor de } \\
\text { Novos Produtos } \\
\text { e Serviços que } \\
\text { responde ao } \\
\text { Vice-Presidente de } \\
\text { Marketing }\end{array}$ & $\begin{array}{l}\text { Não avaliado. } \\
\text { O pesquisador não conseguiu acesso à area. }\end{array}$ \\
\hline Zetha & $\begin{array}{c}\text { Gerência de } \\
\text { Produtos e } \\
\text { Serviços }\end{array}$ & 35 & $\begin{array}{l}\text { Gerente de } \\
\text { Produtos e } \\
\text { Serviços que } \\
\text { responde ao } \\
\text { Diretor de } \\
\text { Marketing }\end{array}$ & $\begin{array}{l}\text { Ela coordena os lançamentos (controle de } \\
\text { cronograma e de custos) de novos produtos e serviços e a } \\
\text { preparação de um plano de negócios que é apresentado para } \\
\text { o board da empresa. Todos os projetos de inovação são } \\
\text { liderados pelos coordenadores dessa área. }\end{array}$ \\
\hline
\end{tabular}


b) Demanda de um cliente externo diretamente para o Setor de Inovação;

c) Demanda interna (normalmente uma área da empresa solicitou a inovação);

d) Iniciativa da alta administração (usualmente do próprio presidente da empresa);

e) Sugestões ou críticas captadas pelo Call Center e que foram direcionadas ao Setor de Inovação;

f) Processo de benchmarking com outras empresas do grupo ou com concorrentes;

g) Ideias que foram geradas por um fornecedor e foram propostas para o Setor de Inovação.

Listadas as possíveis formas de geração de ideias, o passo seguinte foi relacioná-las com as inovações propriamente ditas. A finalidade desse cruzamento foi possibilitar a determinação sobre qual seria a forma mais frequente de uma ideia ser gerada para as inovações em serviços, conforme o Quadro 4.

Como se pode perceber pelo Quadro 4, há casos de inovações em que as ideias foram geradas por meio de mais de uma fonte. Tome-se como exemplo o controle remoto infantil gerado pela empresa Zetha. Foi por meio do Call Center que as reclamações dos usuários pela dificuldade de operação do controle remoto da nova televisão digital foram captadas e direcionadas ao Setor de Inovação (denominado na empresa de Gerência de Produtos e Serviços) para, posteriormente, a ideia ser desenvolvida.

As principais formas de geração de ideias foram propostas pelo Setor de Inovação via ideias oriundas de processos de benchmarking com concorrentes ou outras empresas do grupo. Juntas, estas duas formas estiveram presentes em $40 \%$ dos casos estudados.

Num patamar ligeiramente inferior quanto à forma de geração de ideias empregadas nas inovações dos casos, estão as ideias que nasceram de demandas internas de outras áreas; as ideias que nasceram de sugestões captadas pelo Call Center; e as ideias que foram derivadas do próprio Setor de Inovação das empresas.

\subsubsection{Conversão da ideia em inovação}

\subsubsection{A seleção das ideias}

As inovações rastreadas e estudadas nos casos trouxeram uma descoberta importante que é dissonante com o que foi proposto por Bernardes e Bessa (2007). Esses autores propuseram que o desenvolvimento das inovações em serviços não possuía uma regularidade sistemática. Na maioria dos casos estudados, o processo de seleção de ideias e sua conversão para uma inovação propriamente dita passa por um processo sistemático estruturado, com apresentações rotineiras incluindo a preparação de um plano de negócios e apresentações formais para vários níveis hierárquicos de aprovação, como a diretoria do próprio Setor de Inovação, ou sua aprovação pelo board da empresa, como na empresa Delta.

De modo geral, a ideia é selecionada pelo Setor de Inovação (que, na maior parte dos casos, pertence à área de marketing das empresas) após uma investigação preliminar. O critério mais comum para o Setor de Inovação selecionar a ideia é uma análise de potencial de mercado e projeções futuras acerca dos potenciais ganhos que a inovação trará.

Uma vez selecionada a ideia, é comum a preparação e a apresentação de um plano de negócios formalizado. Algumas informações em comum dos planos de negócios são estudos de potencial de mercado, custos associados às inovações, projeção de vendas/ receita das inovações e cronograma de ações. A ideia que foi previamente selecionada pelo Setor de Inovação é apresentada para um fórum de decisão que pode validar ou rejeitar a proposta. Caso ela seja aprovada, o processo de seleção se encerra e inicia-se o desenvolvimento das ações necessárias para levar a cabo a inovação selecionada. Caso a ideia seja rejeitada, ela normalmente é arquivada no próprio Setor de Inovação.

\subsubsection{Financiamento da ideia}

Foram constatadas nos casos estudados duas possíveis formas de financiamento das ideias, a saber:

- O Setor de Inovação da empresa possui um orçamento que é renovado a cada período contábil adotado pela empresa. Neste caso, fica a cargo do gestor do Setor de Inovação a liberação financeira para custear as inovações que serão lançadas no mercado;

- Caso a inovação demande um montante financeiro que não esteja contemplado no orçamento inicial, normalmente o gestor do Setor de Inovação apresenta uma proposta para o board da empresa a fim de angariar fundos para financiar a inovação.

\subsection{Difusão da ideia}

Para a difusão externa das inovações estudadas foram realizadas campanhas publicitárias, combinando várias mídias possíveis, como propagandas em canais de televisão, mensagens em celulares, $e$-mails enviados para usuários e, em alguns casos, ofertas realizadas pelo próprio operador de Call Center aos clientes potenciais (como na inovação da assistência técnica domiciliar da empresa Delta).

Já no caso da difusão interna, há casos como os da empresa Zetha, em que as inovações são apresentadas para todos os funcionários da empresa em encontros 
Quadro 4. Formas possíveis de geração de ideias.

\begin{tabular}{|c|c|c|c|c|c|c|c|c|c|}
\hline \multicolumn{10}{|c|}{ Formas de geração de ideias } \\
\hline & & $\mathbf{A}$ & B & $\mathbf{C}$ & D & $\mathbf{E}$ & $\mathbf{F}$ & $\mathbf{G}$ & Justificativa \\
\hline \multirow[t]{3}{*}{ Beta } & $\begin{array}{l}\text { Comunicação por } \\
\text { ondas de rádio }\end{array}$ & & & & & & & & $\begin{array}{l}\text { A tecnologia iDEN que permite a comunicação } \\
\text { por ondas de rádio foi desenvolvida por um } \\
\text { fornecedor e proposta para o Setor de Inovação. }\end{array}$ \\
\hline & $\begin{array}{l}\text { Implementação } \\
\text { de URAs }\end{array}$ & & & & & & & & $\begin{array}{c}\text { Em virtude do aumento expressivo do } \\
\mathrm{n}^{\circ} \text { de clientes sem aumento proporcional do } \\
\mathrm{n}^{\mathrm{o}} \text { de operadores, as reclamações captadas } \\
\text { pelo Call Center em relação ao tempo médio } \\
\text { para o atendimento cresceram. A Área de } \\
\text { Customer Care solicitou a adoção de URAs } \\
\text { para reduzir o problema. }\end{array}$ \\
\hline & $\begin{array}{l}\text { Localizador de } \\
\text { Frotas }\end{array}$ & & & & & & & & $\begin{array}{c}\text { A geração da ideia partiu de uma } \\
\text { demanda de um cliente específico do ramo de } \\
\text { seguros para o Setor de Inovação. }\end{array}$ \\
\hline \multirow[t]{2}{*}{ Gama } & $\begin{array}{l}\text { Sistema de } \\
\text { Reconhecimento } \\
\text { de Voz }\end{array}$ & & & & & & & & $\begin{array}{l}\text { O presidente da empresa desejava equiparar as } \\
\text { operações de atendimento às melhores práticas de } \\
\text { outras empresas do grupo no mundo. }\end{array}$ \\
\hline & $\begin{array}{l}\text { Ilha de } \\
\text { Reiteração }\end{array}$ & & & & & & & & $\begin{array}{l}\text { A Diretoria Jurídica solicitou à } \\
\text { Diretoria de Atendimento uma forma } \\
\text { para reduzir o } \mathrm{n}^{\mathbf{o}} \text { de processos judiciais. }\end{array}$ \\
\hline \multirow[t]{2}{*}{ Delta } & $\begin{array}{l}\text { Serviço de Rádio } \\
\text { pela Internet }\end{array}$ & & & & & & & & $\begin{array}{c}\text { O presidente da empresa propôs a criação da rádio } \\
\text { para equiparar o serviço do provedor a outras } \\
\text { empresas similares do mundo. }\end{array}$ \\
\hline & $\begin{array}{l}\text { Assistência } \\
\text { Técnica } \\
\text { Domiciliar }\end{array}$ & & & & & & & & $\begin{array}{l}\text { Como muitos atendimentos não podiam ser } \\
\text { solucionados pelo atendimento humano pelo } \\
\text { Call Center ou pelo acesso remoto, o Setor } \\
\text { de Inovação (Diretoria de Portifólio de Novos } \\
\text { Negócios) propôs a criação de um novo } \\
\text { serviço de assistência técnica domiciliar. }\end{array}$ \\
\hline \multirow[t]{3}{*}{ Kappa } & $\begin{array}{l}\text { Ilha de } \\
\text { atendimento } \\
\text { iPhone }\end{array}$ & & & & & & & & $\begin{array}{l}\text { O presidente da empresa solicitou a } \\
\text { criação de uma ilha de atendimento } \\
\text { específica para os usuários de iPhone. }\end{array}$ \\
\hline & $\begin{array}{l}\text { Sistema de } \\
\text { Faturamento } \\
\text { Unificado }\end{array}$ & & & & & & & & $\begin{array}{l}\text { A Área de Atendimento solicitou uma } \\
\text { alteração no sistema para poder informar valores } \\
\text { relativos às faturas sem haver necessidade de } \\
\text { transferência de chamadas telefônicas. }\end{array}$ \\
\hline & $\begin{array}{l}\text { Utilização do } \\
\text { Windows Live } \\
\text { Messenger }\end{array}$ & & & & & & & & $\begin{array}{c}\text { A Diretoria de Novos Produtos e } \\
\text { Serviços solicitou a um fornecedor o } \\
\text { desenvolvimento de uma versão adapatada } \\
\text { do sistema operacional Windows para } \\
\text { utilização nos aparelhos telefônicos. }\end{array}$ \\
\hline \multirow[t]{6}{*}{ Zetha } & Triple Play & & & & & & & & $\begin{array}{l}\text { A ideia foi gerada pelo Setor de Inovação } \\
\text { (Gerência de Produtos e Serviços) baseada em } \\
\text { modelos similares norte-americanos. }\end{array}$ \\
\hline & $\begin{array}{l}\text { Banda Larga } \\
\text { Ultra-Rápida }\end{array}$ & & & & & & & & $\begin{array}{l}\text { A ideia foi gerada através de um } \\
\text { benchmark com concorrentes. }\end{array}$ \\
\hline & $\begin{array}{l}\text { Controle Remoto } \\
\text { Infantil }\end{array}$ & & & & & & & & $\begin{array}{c}\text { A ideia foi gerada a partir do aumento de } \\
\text { reclamações captadas pelo Call Center em relação } \\
\text { a complexidade de operação do novo controle } \\
\text { remoto da TV Digital. }\end{array}$ \\
\hline & & A & B & $\mathrm{C}$ & $\mathrm{D}$ & $\mathrm{E}$ & $\mathrm{F}$ & G & \\
\hline & Total & 4 & 1 & 3 & 3 & 3 & 4 & 2 & \\
\hline & $\%$ & $20 \%$ & $5 \%$ & $15 \%$ & $15 \%$ & $15 \%$ & $20 \%$ & $10 \%$ & \\
\hline
\end{tabular}

Legenda: (A) Ideias que foram geradas através de propostas do Setor de Inovação; (B) Ideias que nasceram através de uma demanda de um cliente externo diretamente ao Setor de Inovação; (C) Ideias que nasceram de uma de- manda interna (normalmente uma área da empresa solicitou a inovação); (D) Ideias que nasceram através da iniciativa da alta administração (usualmente o próprio presidente); (E) Ideias que nasceram de sugestões ou críticas capta- das pelo Call Center e que foram direcionadas ao Setor de Inovação; (F) Ideias que nasceram de um processo de benchmarking com outras empresas do grupo ou com concorrentes; (G) Ideias que foram geradas por um fornecedor e propostas ao Setor de Inovação. Fonte: Empresas estudadas. 
periódicos de grandes proporções (alguns com mais de dois mil funcionários presentes). Nessas reuniões, o próprio Vice-Presidente de marketing e o Gerente de Produtos e Serviços demonstram os novos produtos e serviços desenvolvidos pela empresa para o público em geral.

Houve também casos de difusão interna para os quais foi criada uma estratégia de divulgação por meio de campanhas internas com a utilização de móbiles, faixas e folhetos que são expostos nas varias áreas da empresa. Um exemplo dessa aplicação foi o ocorrido na empresa Delta para comunicar aos operadores a inovação do serviço de assistência técnica domiciliar. Quando o pesquisador esteve na empresa para as entrevistas, uma Diretora da empresa fez questão de mostrar as faixas desenvolvidas e fixadas em todas as ilhas de atendimento para fácil a visualização dos operadores.

\section{Conclusões}

\subsection{Aderência das proposições teóricas à realidade das empresas estudadas}

Neste ponto do trabalho é conveniente resgatar as proposições anteriormente expostas, contrapondo os dados encontrados nos casos para auxiliar na discussão dos resultados. A seguir se encontram as proposições, bem como as discussões e justificativas adotadas pelos pesquisadores para embasar suas respostas.

P1: As empresas de serviços estudadas possuem uma lógica estruturada para desenvolvimento da inovação, tal como a lógica dos Stage-Gates apresentada por Cooper (1993) para o setor de produtos.

Resultado: Aceita.

Para ilustrar a convergência entre os casos estudados e a referência dos stage-gates foi desenvolvido o Quadro 5, no qual se procurou identificar a presença dos cinco estágios propostos pela estrutura nas inovações estudadas nos casos, a saber: i) Investigação Preliminar; ii) Investigação detalhada e preparação de um plano de negócios; iii) Desenvolvimento da inovação; iv) Teste e validação da inovação; e v) Produção em massa. As evidências encontradas nos casos foram explicitadas em cada uma das fases da estrutura proposta por Cooper (1993) contidas no Quadro 5.

Analisando-se o Quadro 5, nota-se uma clara aderência aos estágios da estrutura de Cooper (1993) na forma pela qual as empresas inovaram nos casos estudados (representada pela cor clara). Com exceção da empresa Kappa (que não foi avaliada nessa categoria de análise), a quase totalidade das empresas apresentou uma lógica de gestão da inovação baseada nas fases e mecanismos de decisão propostas por Cooper (1993).
As exceções em relação à aderência às etapas da estrutura de Cooper foram devidas a algumas particularidades dos casos estudados. Primeiro, no caso da inovação do Rastreador de Frotas, pareceu não fazer sentido a sua produção em massa, posto que se tratou de uma inovação desenvolvida para um cliente em particular a partir de uma necessidade específica. Segundo, nos casos das empresas Delta e Zetha, a ausência da fase da produção em massa deveu-se principalmente ao momento em que o pesquisador esteve nas empresas. É muito provável que estas fases até existam na lógica do processo inovativo das empresas, mas elas não puderam ser confirmadas nos casos estudados, pois, na ocasião em que o pesquisador realizou as entrevistas, as inovações ainda não tinham chegado a esta fase.

P2: O padrão de inovação em serviços das empresas estudadas apresenta características similares aos sistemas "abertos", tal como proposto por Chesbrough (2006).

Resultado: Aceita.

Conforme já mostrado no Quadro 4, algumas fontes geradoras das inovações em serviços estudadas foram o próprio Setor de Inovação, fornecedores, benchmarking com concorrentes, clientes e a alta administração. O uso de múltiplas fontes de inovação em serviços acabou convergindo com os resultados encontrados para a indústria apresentados pela Pintec de 2004, segundo a qual as empresas industriais de bens físicos estão empregando em seus processos de inovações, fontes não apenas internas desenvolvidas por cientistas dedicados nas áreas de Pesquisa e Desenvolvimento, mas também conhecimentos oriundos de fontes diversas. Conforme apontado pela pesquisa conduzida pelo IBGE:

No processo de inovação tecnológica, as empresas podem desenvolver atividades que produzam novos conhecimentos (P\&D) ou utilizar conhecimentos científicos e tecnológicos incorporados nas patentes, máquinas e equipamentos, papers, softwares, etc. Neste processo, as empresas utilizam informações de uma variedade de fontes e a sua habilidade para inovar, certamente, é influenciada por sua capacidade de absorver e combinar tais informações. (INSTITUTO..., 2004, p. 27).

De fato, essa descoberta apresenta também forte relação com a estrutura proposta por Chesbrough (2006) com seu conceito de inovação aberta. Esse autor defende a ideia de que a inovação não deve ser mais alavancada exclusivamente por grandes investimentos em laboratórios de Pesquisa e Desenvolvimento, sendo que a empresa deve buscar caminhos internos e externos para auxiliar no seu processo inovativo.

A heterogeneidade das fontes para geração de ideias encontradas nas empresas estudadas pode, então, ser 
Quadro 5. Evidências encontrados nos casos das fases da estrutura dos Stage-Gates de Cooper (1993).

\begin{tabular}{|c|c|c|c|c|c|}
\hline Empresa & $\begin{array}{l}\text { 1: Investigação } \\
\text { preliminar }\end{array}$ & $\begin{array}{c}\text { 2: Investigação } \\
\text { detalhada e preparação } \\
\text { de um plano de negócios }\end{array}$ & $\begin{array}{l}\text { 3: Desenvolvimento } \\
\text { da inovação }\end{array}$ & $\begin{array}{l}\text { 4: Teste e } \\
\text { validação da } \\
\text { inovação } \\
\end{array}$ & $\begin{array}{l}\text { 5: Produção } \\
\text { em massa }\end{array}$ \\
\hline Beta & $\begin{array}{l}\text { No caso do Localizador } \\
\text { de Frotas a Área de } \\
\text { Marketing conduziu } \\
\text { um estudo preliminar } \\
\text { para analisar, num } \\
\text { primeiro momento, a } \\
\text { questão da viabilidade } \\
\text { tecnológica da } \\
\text { inovação. }\end{array}$ & $\begin{array}{c}\text { Após a sinalização } \\
\text { positiva, foi preparado } \\
\text { um plano de negócios } \\
\text { contendo informações } \\
\text { como o custo da inovação } \\
\text { e o potencial de mercado. } \\
\text { Este plano foi apresentado } \\
\text { formalmente pela Área } \\
\text { de Marketing às Áreas de } \\
\text { Finanças e de Operações. }\end{array}$ & $\begin{array}{c}\text { Uma vez aprovado } \\
\text { o plano de } \\
\text { negócios, a Área } \\
\text { de Marketing } \\
\text { elabora um } \\
\text { cronograma de } \\
\text { ações e o valida } \\
\text { junto a todas as } \\
\text { áreas envolvidas. } \\
\text { Toda gestão do } \\
\text { cronograma é } \\
\text { centralizada na } \\
\text { área de Marketing. }\end{array}$ & $\begin{array}{l}\text { Foi realizado um } \\
\text { teste piloto num } \\
\text { número restrito } \\
\text { de clientes com } \\
\text { a finalidade } \\
\text { de identificar } \\
\text { possíveis falhas } \\
\text { e solucioná-las } \\
\text { antes de } \\
\text { disponibilizar a } \\
\text { inovação para } \\
\text { uma base de } \\
\text { clientes maior. }\end{array}$ & $\begin{array}{l}\text { A inovação do } \\
\text { Localizador } \\
\text { de Frotas foi } \\
\text { desenvolvida } \\
\text { para um cliente } \\
\text { específico e não } \\
\text { foi produzida em } \\
\text { massa. }\end{array}$ \\
\hline Gama & $\begin{array}{l}\text { A área de Inovação } \\
\text { Estratégica foi } \\
\text { encarregada de } \\
\text { preparar um estudo } \\
\text { inicial da viabilidade } \\
\text { da inovação. No } \\
\text { caso do Sistema de } \\
\text { Reconhecimento de } \\
\text { voz foram investigadas } \\
\text { as operações de } \\
\text { outros países que } \\
\text { já utilizavam esta } \\
\text { tecnologia e que } \\
\text { pertenciam ao mesmo } \\
\text { conglomerado de } \\
\text { empresas. }\end{array}$ & $\begin{array}{c}\text { É usual a preparação } \\
\text { de um estudo de caso } \\
\text { (plano de negócios) para } \\
\text { aprovação junto ao board } \\
\text { da empresa. No Sistema de } \\
\text { Reconhecimento de Voz, a } \\
\text { informação de redução de } \\
\text { custos foi fundamental para } \\
\text { a aprovação. }\end{array}$ & $\begin{array}{c}\text { Ficou sob a } \\
\text { responsabilidade } \\
\text { da Vice- } \\
\text { Presidência de } \\
\text { Atendimento a } \\
\text { identificação e o } \\
\text { desenvolvimento } \\
\text { dos potenciais } \\
\text { fornecedores } \\
\text { do sistema } \\
\text { para a Língua } \\
\text { Portuguesa. }\end{array}$ & $\begin{array}{l}\text { A realização } \\
\text { de teste ou } \\
\text { protótipo do } \\
\text { futuro produto ou } \\
\text { serviço foi uma } \\
\text { das fases citadas } \\
\text { pela empresa. } \\
\text { O sistema de } \\
\text { reconhecimento } \\
\text { de voz foi } \\
\text { implementado } \\
\text { inicialmente } \\
\text { apenas para uma } \\
\text { área geográfica } \\
\text { de atuação da } \\
\text { empresa. }\end{array}$ & $\begin{array}{l}\text { Após a validação } \\
\text { do sistema de } \\
\text { reconhecimento } \\
\text { de voz para uma } \\
\text { área restrita, ele foi } \\
\text { disponibilizado para } \\
\text { todos os clientes do } \\
\text { estado. }\end{array}$ \\
\hline Delta & $\begin{array}{c}\text { A diretoria de } \\
\text { Portifólio de } \\
\text { Novos Negócios } \\
\text { juntamente com a } \\
\text { área de atendimento } \\
\text { conduziram um } \\
\text { estudo preliminar para } \\
\text { levantar a existência } \\
\text { de serviços similares } \\
\text { disponíveis no mercado } \\
\text { para o Serviço de } \\
\text { Assistência Técnica } \\
\text { Domiciliar. }\end{array}$ & $\begin{array}{l}\text { Após levantamento inicial, } \\
\text { é responsabilidade da } \\
\text { Diretoria de Portifólio } \\
\text { de Novos Negócios a } \\
\text { elaboração e a apresentação } \\
\text { de um plano de negócios } \\
\text { que contém informações } \\
\text { como i) a motivação da } \\
\text { oportunidade, ii) a prova } \\
\text { de que o serviço ainda não } \\
\text { é fornecido pelo mercado, } \\
\text { iii) o desenvolvimento } \\
\text { do fluxo financeiro e do } \\
\text { retorno projetado em cinco } \\
\text { anos; iv) a apresentação } \\
\text { das ações necessárias } \\
\text { com áreas e recursos } \\
\text { envolvidos. }\end{array}$ & $\begin{array}{c}\text { Uma vez } \\
\text { aprovado o plano } \\
\text { de negócios, } \\
\text { a diretoria de } \\
\text { portifólio de } \\
\text { Novos Negócios } \\
\text { coordenou as } \\
\text { ações necessárias } \\
\text { para levar a cabo } \\
\text { a inovação. No } \\
\text { caso estudado, a } \\
\text { etapa mais crítica } \\
\text { foi a seleção do } \\
\text { parceiro que iria } \\
\text { atuar em todo } \\
\text { território nacional. }\end{array}$ & $\begin{array}{c}\text { Como teste } \\
\text { piloto, o serviço } \\
\text { de Assistência } \\
\text { Técnica } \\
\text { Domiciliar foi } \\
\text { oferecido apenas } \\
\text { para as regiões } \\
\text { de Campinas e } \\
\text { Curitiba. }\end{array}$ & $\begin{array}{c}\text { Durante a } \\
\text { elaboração do caso, } \\
\text { a empresa ainda } \\
\text { não tinha chegado } \\
\text { a esta fase, mas } \\
\text { os entrevistados } \\
\text { ressaltaram que } \\
\text { após alguns ajustes } \\
\text { nos casos piloto, a } \\
\text { inovação do serviço } \\
\text { de Assistêcia } \\
\text { Técnica Domiciliar } \\
\text { será oferecida } \\
\text { nacionalmente. }\end{array}$ \\
\hline Zetha & $\begin{array}{l}\text { A área de Produtos e } \\
\text { Serviços preparou um } \\
\text { pré-projeto do Controle } \\
\text { Remoto infantil que } \\
\text { continha informações } \\
\text { preliminares em } \\
\text { relação aos potenciais } \\
\text { retornos (financeiros } \\
\text { e não-financeiros) da } \\
\text { inovação. }\end{array}$ & $\begin{array}{l}\text { Com o aval da Diretoria } \\
\text { de Marketing para o pré- } \\
\text { projeto, partiu-se para a } \\
\text { elaboração de um estudo } \\
\text { formal num formulário } \\
\text { específico que foi } \\
\text { apresentado para o board } \\
\text { da empresa. }\end{array}$ & $\begin{array}{c}\text { Uma vez aprovado } \\
\text { o projeto no board } \\
\text { da empresa, a } \\
\text { área de Produtos } \\
\text { e Serviços ficou } \\
\text { responsável pelo } \\
\text { gerenciamento das } \\
\text { ações necessárias } \\
\text { para o lançamento } \\
\text { do Controle } \\
\text { Remoto Infantil. }\end{array}$ & $\begin{array}{c}\text { O Controle } \\
\text { Remoto } \\
\text { Infantil foi } \\
\text { disponibilizado } \\
\text { gratuitamente } \\
\text { para um grupo } \\
\text { específico } \\
\text { de clientes, } \\
\text { determinado pelo } \\
\text { valor da fatura, } \\
\text { área geográfica } \\
\text { e quantidade de } \\
\text { filhos. }\end{array}$ & $\begin{array}{c}\text { Durante a } \\
\text { elaboração do caso, } \\
\text { a empresa também } \\
\text { não havia chegado } \\
\text { a esta fase, pois os } \\
\text { ajustes no aparelho } \\
\text { ainda estavam } \\
\text { sendo efetuados } \\
\text { pelo fornecedor. } \\
\text { Entretanto, } \\
\text { os executivos } \\
\text { entrevistados } \\
\text { garantiram que } \\
\text { a inovação seria } \\
\text { produzida em massa } \\
\text { num momento } \\
\text { posterior. }\end{array}$ \\
\hline
\end{tabular}


fruto de tentativas das empresas de serviço estudadas para compensar a falta de grandes investimentos em Laboratórios de Pesquisa e Desenvolvimento. Dessa forma, pelo que foi encontrado nos casos, não seria demasiadamente arriscado afirmar que a inovação em serviços segue a lógica proposta por Chesbrough (2006), da inovação aberta.

\subsection{As limitações do trabalho}

A escolha pelo método do estudo de caso foi impulsionada por uma constatação já apontada pelos pesquisadores e que foi identificada durante a fase de levantamento bibliográfico: a maioria dos trabalhos existentes tratou a questão da inovação sob uma perspectiva econômica, utilizando bases de dados secundárias como pesquisas produzidas pela OECD, Pintec ou PAEP; poucos trabalhos trataram a questão da inovação sob outro ponto de vista, isto é, investigar como a inovação ocorre sob a ótica da empresa, quais áreas são mobilizadas, quais os critérios empregados pela empresa para avaliar e levar a cabo a inovação propriamente dita.

A primeira limitação deste artigo decorre desta escolha, aproveitando a lacuna de pesquisa identificada, e optando por estudar casos de empresas reais que colocaram suas inovações no mercado. É sabido que, em estudo de casos, os resultados da pesquisa são de difícil generalização. Desta forma, os pesquisadores têm plena ciência dos limites deste trabalho, na medida em que ele foi um estudo de caso múltiplo, sendo seu poder de generalização restrito.

Todavia, a metodologia escolhida foi determinante no sentido de promover uma melhor compreensão sobre o modelo de gestão de inovação das empresas de serviço.

Isto não significa em absoluto que outras empresas de serviço inovem da mesma forma que as empresas pesquisadas. Seria conveniente e necessário, em termos de generalização de uma teoria, que outros serviços fossem estudados.

\subsection{Considerações finais}

Pode-se destacar que uma contribuição fundamental deste trabalho foi estudar o fenômeno da inovação em serviços sob um ponto de vista distinto de trabalhos anteriores que utilizaram dados agregados de pesquisas setoriais como Gallouj (2007), Tidd e Hull (2005), Miles (2005), Bernardes e Kallup (2006) ou Kubota (2000). Diferentemente desses trabalhos, que abordaram a questão da inovação sob uma ótica exógena à empresa, este trabalho optou por seguir uma linha de pensamento segundo a qual, para se estudar e compreender o funcionamento do processo inovativo, primeiramente se deve entrar nas organizações e investigar com maior profundidade os casos individuais.

Estudando-se os casos de inovações das empresas de serviços, percebeu-se que a Inovação segue uma lógica similar em relação às inovações encontradas na literatura para bens físicos. Mas isso não que dizer que a lógica é absolutamente idêntica. Há nuances. Para exemplificar, nos casos estudados não foram encontrados departamentos específicos de pesquisa e desenvolvimento, com a presença de cientistas e/ ou técnicos exclusivamente dedicados às atividades que promovam a inovação. Contudo, as empresas de serviço possuíam sempre um Setor de Inovação com pessoas trabalhando para essa finalidade. Esse setor normalmente esteve associado às áreas de marketing das empresas. Também foi encontrada nas organizações de serviço a função de um executivo que centralizou as principais decisões dos projetos de inovações, usualmente apresentados para um comitê decisor. Estas descobertas contribuíram para uma melhor compreensão da inovação no setor de serviços.

\section{Referências}

BARDIN, L. Análise de Conteúdo. Lisboa: Edições 70, 2000.

BARRAS, R. Towards s theory of innovation in services. Research Policy, v.15, p. 161-174, 1986.

BERNARDES, R. C.; BESSA, V. Novos Campos Teóricos e Desafios Métricos nos Estudos de Inovação entre indústria e serviços. In: BERNARDES, R.; ANDREASSI, T. (Orgs.). Inovação em Serviços Intensivos em Conhecimento. São Paulo: Saraiva, 2007.

BERNARDES, R. C; KALLUP, A. A Emergência dos Serviços Intensivos em Conhecimento no Brasil. In: BERNARDES, R.; ANDREASSI, T. (Orgs.). Inovação em Serviços Intensivos em Conhecimento. São Paulo: Saraiva, 2007.

BILDERBEEK, R. et al. Innovation in Services. Oslo, Noruega, 1998. (SI4S - Syntehesis Paper, n. 3). Disponível em: <http://www.step.no/old/projectarea/ si4s/index.htm>. Acesso em: 06 out. 2008.

CHESBROUGH, H. Open INNOVATION: THE NEW IMPERATIVE FOR CREATING AND PROFITING FROM TECHNOLOG. Harvard Business School Press, 2006.

COOPER, R. G. Stage -gate systems: a new tool for managing new products. Business Horizons, p. 45-55, 1990.

COOPER, R.G. Winning at new products: accelerating the process from idea to launch. New York: Addison-Wesley, 1993.

EDQUIST, C. (Ed.). Systems of Innovation: technologies, institutions and organizations. Londres: Printer Publisher, 1997.

FUNDAÇÃO SISTEMA ESTADUAL DE ANÁLISE DE DADOS - SEADE. Pesquisa da Atividade Econômica Paulista - PAEP. Principais Resultados. São Paulo: Fundação SEADE, 2001. Disponível em: <http://www. seade.gov.br/produtos/paep>. Acesso em: 07 nov. 2008. 
GALLOUJ, F. Economia da Inovação: Um balanço dos debates recentes. In: BERNARDES, R.; ANDREASSI, T. (Orgs.). Inovação em Serviços Intensivos em Conhecimento. São Paulo: Saraiva, 2007.

GALLOUJ, F.; WEINSTEIN, O. Inovation in Services. Research Policy, v. 26, p. 537-556, 1997. http://dx.doi. org/10.1016/S0048-7333(97)00030-9

GOLDRATT, E. M. Theory of Constraints, North River Press. New York: Croton-on-Hudson, 1993.

HANSEN, M. T.; BIRKINSHAW, J. The Innovation Value Chain. Harvard Business Review, 2007.

INSTITUTO BRASILEIRO DE GEOGRAFIA E ESTATÍSTICA - IBGE. Pesquisa Industrial de Inovação Tecnológica - PINTEC-2004. Relatório Metodológico. Rio de Janeiro: IBGE, 2004. vol. 30.

KUBOTA, L. C. A inovação tecnológica das firmas de serviços no Brasil. In: DE NEGRI, J. A.; KUBOTA, L. C. (Org.). Estrutura e Dinâmica do Setor de Serviços no Brasil. Brasília: IPEA, 2000. v. 1, p. 35-72.

KUBOTA, L.C. As Kibs e a inovação tecnológica das firmas de serviços. Economia e Sociedade, Campinas, v. 18, n. 2 (36), p. 349-369, ago. 2009.

MALHORTA, N. Pesquisa em Marketing: uma orientação aplicada. 5. ed. São Paulo: Bookman, 2004.

MARKLUND, G. Indicators of innovation activities in services. In: BONDEN, M.; MILES, I. Services and the knowledge based economy. London, New York: Ed. Continuum, 2000.

MILES, I. Knowledge-Intensive Business Services: prospect and policies. Foresight, v. 7, n. 6, p. 39-63, 2005.
MILLES, I. Serviços e Inovação na Europa In: BERNARDES, R.; ANDREASSI, T. (Orgs.). Inovação em Serviços Intensivos em Conhecimento. São Paulo: Saraiva 2007.

OECD - Organization for Economic Co-Operation and Development. Promoting innovation in services. Paris: OECD, 2005.

ROGERS, E. M; SHOEMAKER, F. F. Communication of Innovations: a Cross Cultural Approach. New York: Free Press, 1971.

SCHUMPETER, J. Teoria do desenvolvimento econômico. São Paulo: Abril Cultural, 1982.

SOUZA, R.; VOSS, C. Quality Management: Universal or Context Dependent? Production and Operations Management, v.10, n. 4, p. 383-404, 2001.

SUNDBO, J.; GALLOUJ, F. Innovation in Service. Manchester, 1998. Policy Research in Engineering, Sciense \& Technology - PREST. Project Report S2.

TIDD, J. HULL, F. M. Service Innovation: Organizational Responses Technological Opportunities e Market Imperatives. Imperial College Press, 2005.

VERMEULEN, P.; VAN DER AA, W. Organaizing Innovation in Services. In: TIDD, J.; HULL, F. M. Service Innovation. Organizational Responses Technological Opportunities e Market Imperatives, Imperial College Press, 2005.

YIN, R. Estudo de caso: Planejamento e Métodos. Porto Alegre: Ed. Bookman, 2005. 